\title{
EXTENSÃO UNIVERSITÁRIA NO CURSO DE PUBLICIDADE E PROPAGANDA: PERSPECTIVAS ACADÊMICAS E COMUNITÁRIAS DO PROJETO COMUNICAÇÃO PARA O DESENVOLVIMENTO SOCIAL
}

Fabricia Durieux Zucco Universidade Regional de Blumenau fabriciazucco@hotmail.com

Cynthia Morgana Boos de Quadros Universidade Regional de Blumenau cynthiadequadros@gmail.com

Rafael Jose Bona Universidade Regional de Blumenau rafaeljosebona@gmail.com

Resumo

O presente artigo analisa a percepção do estudante de Publicidade e Propaganda da Universidade Regional de Blumenau (FURB) em relação às diferentes dimensões da extensão universitária e especificamente ao projeto "Comunicação para o desenvolvimento social". A partir de uma pesquisa quantitativa, o artigo apresenta as percepções dos acadêmicos acerca do papel da FURB na comunidade; papel pessoal na comunidade; papel da comunidade na formação pessoal; papel do curso na comunidade; papel pessoal na comunidade; papel da comunidade na formação pessoal; valorização da extensão e valorização do projeto de comunicação para ONGs. Os resultados indicam uma alta valoração por parte dos acadêmicos em relação às atividades comunitárias nas diferentes dimensões.

Palavras-chave: Extensão. Comunicação Comunitária. Publicidade.

\section{UNIVERSITY EXTENSION PROGRAM IN ADVERTISING COURSE: ACADEMIC AND COMMUNITY PERSPECTIVES OF THE PROJECT COMMUNICATION FOR SOCIAL DEVELOPMENT}

\begin{abstract}
The present article analyzes the perception of the student of Advertising of the FURB in relation to the different dimensions of the university extension and specifically to the project "Communication for the social development". From a quantitative research, the article presents the perceptions of scholars about the Role of FURB in the community; Personal role in the community; Role of the community in personal formation; Role of the course in the community; Personal role in the community; Role of the community in personal formation; Valuation of the extension and Valorization of the communication project for NGOs. The results indicate a high valuation by the academics for the community activities in the different dimensions.

Keywords: Extension. Community Communication. Publicity.

\section{EXTENSIÓN UNIVERSITARIA NEL CURSO DE PUBLICIDAD: PERSPECTIVAS ACADÉMICAS Y COMUNITARIAS DEL PROYECTO COMUNICACIÓN PARA EL DESARROLLO SOCIAL}

\section{Resumen}

El presente artículo analiza la percepción del estudiante de Publicidad de la FURB en relación a las diferentes dimensiones de la extensión universitaria y específicamente al proyecto "Comunicación para el desarrollo social". A partir de una investigación cuantitativa, el artículo presenta las percepciones de los académicos acerca del papel de la FURB en la comunidad; Papel personal en la comunidad; Papel de la comunidad en la formación personal; Papel del curso en la comunidad; Papel personal en la comunidad; Papel de la comunidad en la formación personal; Valorización de la extensión y valorización del proyecto de comunicación para ONGs. Los resultados indican una alta valoración por parte de los académicos para las actividades comunitarias en las diferentes dimensiones.

Palabras clave: Extensión. Comunicación Comunitaria. Publicidad. 
Extensão universitária no curso de Publicidade e Propaganda: perspectivas acadêmicas e comunitárias do projeto comunicação para o desenvolvimento social

\section{INTRODUÇÃO}

O fortalecimento da demanda por socialização do conhecimento tem desafiado as universidades brasileiras a estabelecerem relações efetivas e dinâmicas com as comunidades nas quais estão inseridas. As instituições de ensino superior vêm sendo reivindicadas por práticas de ensino, pesquisa e extensão pautadas em pensamento crítico e capazes de criar espaços democráticos, multiculturais e catalisadores de ações coletivas transformadoras.

Em suma, a universidade é constantemente instigada a "potencializar mudanças nas esferas essenciais em direção dos valores universais de desenvolvimento humano", conjugando-as "com as transformações em nível de consciência individual e com as mudanças dos processos coletivos" (MINAYO, 2005, p. 69). Também opera de modo a dialogar com diferentes atores e respeitar a alteridade e as contribuições históricas e culturais das populações com as quais interage.

Esse diálogo deve ser entendido como "uma espécie de postura necessária, na medida em que os seres humanos se transformam cada vez mais em seres criticamente comunicativos. O diálogo é o momento em que os humanos se encontram para refletir sobre sua realidade tal como a fazem e re-fazem" (FREIRE; SHOR, 2003, p. 123).

Nesse contexto se insere a extensão universitária, definida na Política Nacional de Extensão Universitária, elaborada pelo Fórum de Pró-Reitores de Extensão das Instituições Públicas de Educação Superior Brasileiras (Forproex), como "um processo interdisciplinar, educativo, cultural, científico e político que promove a interação transformadora entre Universidade e outros setores da sociedade" (FORPROEX, 2012, p. 15). Destaca-se que o Plano Nacional de Educação (BRASIL, 2014) inclui, entre as estratégias da meta 12, “assegurar, no mínimo, dez por cento do total de créditos curriculares exigidos para a graduação em programas e projetos de extensão universitária, orientando sua ação, prioritariamente, para áreas de grande pertinência social".

Atenta a essas questões, a Universidade Regional de Blumenau (FURB), situada no município de Blumenau, em Santa Catarina, desenvolve uma série de projetos de extensão voltados a impulsionar o desenvolvimento local e regional, a partir da compreensão do contexto sociocultural e do ecossistema comunicacional do território no qual atua, buscando, em todos os processos, aproximação e integração da academia com a comunidade.

Um deles é o projeto intitulado "Comunicação para o desenvolvimento social", realizado pelo curso de Publicidade e Propaganda, cujo objetivo é estimular a cooperação 
Extensão universitária no curso de Publicidade e Propaganda: perspectivas acadêmicas e comunitárias do projeto comunicação para o desenvolvimento social

técnica com organizações não governamentais (ONGs) de Blumenau, por meio do desenvolvimento de campanhas de comunicação para o uso estratégico da publicidade como ferramenta de mobilização da opinião pública e captação de recursos e voluntários. A proposta é produzir, de modo cooperado, material publicitário a ser utilizado como suporte às ações das entidades envolvidas e, ao mesmo tempo, oferecer, a estudantes e professores da FURB, experiências significativas que lhes proporcionem aliar a teoria a uma prática coletiva, reflexiva e crítica que tenha como base a comunicação e o diálogo. Nos últimos anos, o projeto tem se dedicado a conceber peças publicitárias (cartazes, outdoor, leiaute para redes sociais digitais etc.) para as ONGs blumenauenses que vão desde casas de apoio a pessoas da terceira idade, assim como, para associação de proteção de animais de rua.

As atividades vêm sendo executadas com sucesso há doze anos ininterruptos e beneficiado uma série de organizações de Blumenau e região. Contudo, pouco ainda se sabe a respeito de como os acadêmicos participantes percebem a importância das práticas de extensão para sua formação e sua carreira. A partir dessa constatação, este artigo tem o objetivo de analisar a percepção do estudante de Publicidade e Propaganda, da FURB, em relação às diferentes dimensões da extensão universitária e especificamente ao projeto “Comunicação para o desenvolvimento social". Ressalta-se que o projeto possui instrumentos específicos para avaliação por vários atores sociais envolvidos, mas se apresenta aqui apenas a avaliação na perspectiva dos acadêmicos do curso.

\section{UNIVERSIDADE, SOCIEDADE E EXTENSÃO}

Universidade é "uma instituição social e se molda às diferentes configurações sociais registradas na história" (CASTANHO, 2000, p. 23), "um microcosmo que exprime como os conhecimentos e a cultura se acham integrados numa dada sociedade e em função de que fins" (JANNE, 1981, p. 40).

Considerando ser ela "o lugar privilegiado de produção de conhecimento, o ponto germinal donde derivam para o futuro os produtores de conhecimento, à altura dos desafios dos novos tempos" (MENESES, 2001, p. 19), pode-se, então, "resumir o mandato da universidade como sendo de educar novas gerações e formar profissionais inovadores, com qualidade formal e política" (DEMO, 2001, p. 4).

Göransson, Maharajh e Schmoch (2009) afirmam que cabe à universidade incentivar o uso do conhecimento nela produzido, no sentido de contribuir para o 
Extensão universitária no curso de Publicidade e Propaganda: perspectivas acadêmicas e comunitárias do projeto comunicação para o desenvolvimento social

desenvolvimento sociocultural e econômico. Para além disso, importa entender que "o conhecimento não é só uma construção social como também uma possibilidade de resgatar a dignidade do ser humano no interior da cultura à qual pertencemos" (GHEDIN, 2005, p. 141), sendo, cada sujeito, "produtor de um conhecimento que se faz como práxis comprometida politicamente" (GHEDIN, 2005, p. 147).

Assim, a Universidade tem o dever de construir nos seus alunos habilidades, estratégias específicas necessárias ao processamento e ao domínio do conhecimento socialmente produzido, para que possa obter sua independência e autonomia na construção e reconstrução contínua de sua história como sujeito social participante de uma sociedade mais democrática (PEREIRA, 2011, p. 18).

Assim, é inadmissível que as universidades operem como "fábricas de diplomas, pesquisando pouco ou nada e não se projetando significativamente à comunidade" (BORDENAVE, 2005, p. 49). Importante acréscimo a essa discussão faz Chagas (2004, p. 3), ao enfatizar que não há como o conhecimento acadêmico "ser estendido a faixas mais amplas da sociedade" enquanto a universidade não for "livre e crítica" na produção do conhecimento e não conseguir "neutralizar relações sociais marcadamente segmentadoras e elitistas" na formação de profissionais.

A extensão universitária é compreendida como processo educativo, cultural e científico, que articula o ensino e a pesquisa de forma indissociável e viabiliza a relação transformadora entre a universidade e a sociedade, como via de mão dupla, com livre trânsito assegurado à comunidade acadêmica, que encontrará na sociedade a oportunidade da prática de um conhecimento acadêmico, e como interação da universidade com a sociedade, com as comunidades externas em suas mais diferentes formas de organização, que estabelece uma troca de saberes acadêmico e popular, possibilitando a produção do conhecimento resultante do confronto com a realidade nacional, a democratização do conhecimento acadêmico e a participação efetiva da comunidade na atuação da universidade (FORPROEX, 2012, s/p.).

Calderón (2011) parte desse entendimento para indicar sete dimensões da extensão. As três primeiras são a ética (capacidade de questionar, de forma contínua e permanente, os rumos das atividades de ensino e pesquisa e as práticas gerenciais); a formadora (para a cidadania, possibilitando espaços para que estudantes, professores e parceiros vivenciem valores democráticos que favoreçam o respeito aos direitos humanos, a transparência das ações governamentais e a construção de uma sociedade inclusiva, multicultural e ecologicamente equilibrada). E, a acadêmica, que rompe os muros da sala de aula e dos laboratórios de pesquisa para se tornar ação sistemática geradora de conhecimentos e da vivência cidadã. 
Extensão universitária no curso de Publicidade e Propaganda: perspectivas acadêmicas e comunitárias do projeto comunicação para o desenvolvimento social

A extensão deve ser vista como “uma 'ação política' de presença da universidade no processo de desenvolvimento, isto é, como uma presença ativa e construtiva de intervenção da universidade na dinâmica do desenvolvimento da sociedade" (FRANTZ, 2011, p. 127). O autor ressalta que a extensão, articulada com a pesquisa, pode ser compreendida como “uma 'ação-reflexão' no processo de desenvolvimento da sociedade. A extensão 'vivifica' a relação da universidade com a sociedade, especialmente, em âmbitos locais ou regionais" (FRANTZ, 2011, p. 127).

\section{HIPÓTESES}

As hipóteses, a seguir, foram concebidas a partir da revisão bibliográfica e de uma análise do cenário social das práticas de extensão no município de Blumenau, por meio da FURB. Essas referidas hipóteses também se estruturam por meio de dois trabalhos anteriores (ZUCCO, QUADROS, BONA, 2017; ZUCCO ET AL., 2016) que dialogam acerca dos estudantes de Publicidade e Propaganda e sua relação com o envolvimento comunitário.

Hipótese 1: Quanto maior for o papel da universidade na comunidade percebido pelo estudante, maior será a valorização da extensão para este estudante.

Hipótese 2: Quanto maior for o papel da universidade na comunidade percebido pelo estudante, maior será o papel da comunidade na formação pessoal para o estudante.

Hipótese 3: Quanto maior for o papel do curso na comunidade percebido pelo estudante, maior será a valorização da extensão para este estudante.

Hipótese 4: Quanto maior for o papel do curso na comunidade percebido pelo estudante, maior será o papel da comunidade na formação pessoal para o estudante.

Hipótese 5: Quanto maior for o papel pessoal na comunidade percebido pelo estudante, maior será a valorização da extensão para este estudante.

Hipótese 6: Quanto maior for o papel pessoal na comunidade percebido pelo estudante, maior será o papel da comunidade na formação pessoal para o estudante.

Hipótese 7: Quanto maior for a valorização dada a extensão pelo estudante, maior será a valorização do projeto de comunicação para ONGs dada pelo estudante.

Hipótese 8: Quanto maior for a percepsão do papel da comunidade na formação do estudante, maior será a valorização dada pelo estudante ao projeto de comunicação para ONGs. 
Extensão universitária no curso de Publicidade e Propaganda: perspectivas acadêmicas e comunitárias do projeto comunicação para o desenvolvimento social

\section{MÉTODO}

Metodologicamente, este estudo assenta em um levantamento de dados junto a estudantes de graduação na Universidade Regional de Blumenau. O estudo teve como foco os efeitos das visões pessoais dos estudantes sobre o papel da universidade, do curso de Publicidade e Propaganda e seu papel pessoal na comunidade sobre sua visão da extensão e do projeto de extensão de campanhas publicitárias para ONGs.

Para o cumprimento do objetivo proposto, utilizou-se o método quantitativo. O instrumento de coleta de dados usado foi o questionário estruturado com perguntas fechadas e autopreenchível. Nesse instrumento foi usada a escala Likert de cinco pontos, que consiste em uma ferramenta que busca escalonar variáveis utilizando os pontos mais baixos para total discordância do entrevistado em relação à afirmação e os pontos mais altos para total concordância. A pesquisa foi aplicada no segundo semestre de 2017.

\section{VARIÁVEIS}

As variáveis do estudo foram coletadas em forma de questionário (survey). As questões que conceberam as variáveis foram desenvolvidas por uma junta de três especialistas, que estruturaram as questões, posteriormente validadas por três outros especialistas com o método de correspondência de dimensões. O questionário foi posteriormente submetido a um pré-teste com 20 respondentes, no qual não foram constatados problemas. Depois de validado ele conteve as seguintes dimensões:

\section{Papel da universidade na comunidade}

A dimensão "Papel da universidade na comunidade" tem como objetivo mensurar a percepção do estudante quanto ao papel da FURB na sua relação com a sociedade. Escores mais altos nesta dimensão indicam que o acadêmico vê a universidade como um elemento importante na comunidade e que o auxílio à comunidade regional é uma de suas funções. Esta dimensão conteve questões como "O papel da Universidade também é promover o desenvolvimento da comunidade de Blumenau e região" e "A FURB, por meio de suas atividades de pesquisa e extensão, possibilita aos seus alunos um maior envolvimento com a comunidade de Blumenau e região". 
Extensão universitária no curso de Publicidade e Propaganda: perspectivas acadêmicas e comunitárias do projeto comunicação para o desenvolvimento social

\section{Papel do curso de publicidade e propaganda na comunidade}

A dimensão "Papel do curso na comunidade" se assemelha à dimensão "papel da universidade na comunidade", porém, nesta dimensão, o estudante é indagado sobre sua percepção a respeito da função do curso específico de Publicidade e Propaganda da FURB como um suporte à comunidade. Esta dimensão foi composta por questões como "O meu curso oferece diferentes maneiras de contribuir para o desenvolvimento da comunidade de Blumenau e região" e "Algumas atividades desenvolvidas em sala de aula também têm o propósito de integrar os alunos do curso com o cenário local”.

\section{Papel pessoal na comunidade}

A dimensão "Papel pessoal na comunidade" corresponde à visão do estudante sobre sua própria função de auxílio à comunidade e ao desenvolvimento da região. Diferentemente das dimensões supracitadas, esta diz respeito apenas à função específica do indivíduo e não de um grupo como a universidade ou o curso. Esta dimensão foi constituída por questões como "Na maioria das vezes, preocupo-me verdadeiramente com as pessoas ou com as causas as quais me dedico" e "Trabalhar em prol da minha comunidade me permite ganhar uma nova perspectiva sobre as coisas".

\section{Papel da comunidade na formação pessoal}

A dimensão "Papel da comunidade na formação pessoal" envolve a visão do aluno sobre o quão importante é a relação direta dele com a comunidade e com seu desenvolvimento na sua formação pessoal. Em outras palavras, captura o quanto o envolvimento com a comunidade é visto pelo estudante como positivo para seu futuro. Esta dimensão foi composta por itens como "Ter um envolvimento com a comunidade contribui para a minha formação profissional, ampliando meus conhecimentos e experiências" e "Ter proximidade com o cenário local, conhecendo diferentes aspectos econômicos, políticos e sociais da comunidade, é um diferencial competitivo para o profissional de Publicidade e Propaganda".

\section{Valorização da extensão}

A dimensão "Valorização da extensão" se caracteriza pelo quanto o estudante percebe a extensão como uma parte inexorável da universidade e a vê como algo positivo e necessário. Foi composta por questões como: “Os projetos de extensão de Publicidade são 
Extensão universitária no curso de Publicidade e Propaganda: perspectivas acadêmicas e comunitárias do projeto comunicação para o desenvolvimento social

motivo de orgulho para os estudantes do curso" e "Esses projetos são considerados pelos alunos de Publicidade como um dos grandes diferenciais do Curso".

\section{Valorização do projeto comunicação para o desenvolvimento social}

A dimensão "Valorização do projeto Comunicação para o Desenvolvimento Social" representa o quanto o estudante valoriza o projeto em específico. Foi composta pelos itens "Contribui para o desenvolvimento da cidade", "Aproxima e promove contatos entre estudantes e o mercado profissional" e "Coloca em prática as teorias estudadas em sala de aula".

\section{Amostra}

No contexto da população, 307 estudantes matriculados no curso de Publicidade e Propaganda da FURB, considerou-se como amostra os 182 alunos que indicaram conhecimento do projeto em estudo por meio da pergunta-filtro. Os dados sobre as características da amostra se encontram na tabela 1.

\section{Gênero}

\begin{tabular}{|l|r|r|r|r|}
\hline & Frequência & Porcentual & $\begin{array}{c}\text { Porcentagem } \\
\text { válida }\end{array}$ & $\begin{array}{c}\text { Porcentagem } \\
\text { acumulativa }\end{array}$ \\
\hline Não & 1 &, 5 &, 5 &, 5 \\
respondeu & 77 & 42,3 & 42,3 & 42,9 \\
Homens & 104 & 57,1 & 57,1 & 100,0 \\
Mulheres & 182 & 100,0 & 100,0 & \\
Total & & & \\
\hline
\end{tabular}

Idade

\begin{tabular}{|l|r|r|r|r|}
\hline & Frequência & Porcentual & $\begin{array}{c}\text { Porcentagem } \\
\text { válida }\end{array}$ & $\begin{array}{c}\text { Porcentagem } \\
\text { acumulativa }\end{array}$ \\
\hline Não & 3 & 1,6 & 1,6 & 1,6 \\
respondeu & 30 & 16,5 & 16,5 & 18,1 \\
Até 18 & 120 & 65,9 & 65,9 & 84,1 \\
19 a 22 & 25 & 13,7 & 13,7 & 97,8 \\
23 a 25 & 4 & 2,2 & 2,2 & 100,0 \\
Mais de 26 & 182 & 100,0 & 100,0 & \\
Total & & &
\end{tabular}


Extensão universitária no curso de Publicidade e Propaganda: perspectivas acadêmicas e comunitárias do projeto comunicação para o desenvolvimento social

Fase do Curso

\begin{tabular}{|l|r|r|r|r|}
\hline & Frequência & Porcentual & $\begin{array}{c}\text { Porcentagem } \\
\text { válida }\end{array}$ & $\begin{array}{c}\text { Porcentagem } \\
\text { acumulativa }\end{array}$ \\
\hline Não & 2 & 1,1 & 1,1 & 1,1 \\
Respondeu & 27 & 14,8 & 14,8 & 15,9 \\
1 & 21 & 11,5 & 11,5 & 27,5 \\
2 & 17 & 9,3 & 9,3 & 36,8 \\
3 & 16 & 8,8 & 8,8 & 45,6 \\
4 & 5 & 2,7 & 2,7 & 48,4 \\
5 & 44 & 24,2 & 24,2 & 72,5 \\
6 & 16 & 8,8 & 8,8 & 81,3 \\
7 & 34 & 18,7 & 18,7 & 100,0 \\
8 & 182 & 100,0 & 100,0 & \\
Total & & & \\
\hline
\end{tabular}

Renda familiar mensal

\begin{tabular}{|l|r|r|r|r|}
\hline & Frequência & Porcentual & $\begin{array}{c}\text { Porcentagem } \\
\text { válida }\end{array}$ & $\begin{array}{c}\text { Porcentagem } \\
\text { acumulativa }\end{array}$ \\
\hline Não & 19 & 10,4 & 10,4 & 10,4 \\
respondeu & 30 & 16,5 & 16,5 & 26,9 \\
Até 3748 & 84 & 46,2 & 46,2 & 73,1 \\
3749 a 9370 & 47 & 25,8 & 25,8 & 98,9 \\
Acima de 9371 & 2 & 1,1 & 1,1 & 100,0 \\
Se recusou & 182 & 100,0 & 100,0 & \\
Total & & & &
\end{tabular}

Tabela 1 Características da amostra

Fonte: dados da pesquisa.

\section{RESULTADOS}

A tabela 2 apresenta as estatísticas descritivas do levantamento, demonstrando a média e desvio padrão correspondente a cada dimensão e às variáveis que a compõem. 
Extensão universitária no curso de Publicidade e Propaganda: perspectivas acadêmicas e comunitárias do projeto comunicação para o desenvolvimento social

\begin{tabular}{|c|c|c|c|c|c|}
\hline & $\mathrm{N}$ & Mínimo & Máximo & Média & $\begin{array}{l}\text { Desvio } \\
\text { padrão }\end{array}$ \\
\hline Papel da Universidade na comunidade & 182 & 2,00 & 5,00 & 4,17 & 0,56 \\
\hline $\begin{array}{l}\text { O papel da Universidade também é promover o } \\
\text { desenvolvimento da comunidade de Blumenau e região. }\end{array}$ & 182 & 1,00 & 5,00 & 4,45 & 0,67 \\
\hline $\begin{array}{l}\text { A FURB, por meio de suas atividades de pesquisa e } \\
\text { extensão, possibilita aos seus alunos um maior } \\
\text { envolvimento com a comunidade de Blumenau e região. }\end{array}$ & 182 & 1,00 & 5,00 & 4,29 & 0,79 \\
\hline $\begin{array}{l}\text { Os alunos da FURB costumam realizar atividades com o } \\
\text { objetivo de melhorar a vida das pessoas de Blumenau e } \\
\text { região. }\end{array}$ & 182 & 1,00 & 5,00 & 3,75 & 0,87 \\
\hline Papel do Curso na comunidade & 182 & 2,00 & 5,00 & 4,06 & 0,67 \\
\hline $\begin{array}{l}\text { O meu curso oferece diferentes maneiras de contribuir } \\
\text { para o desenvolvimento da comunidade de Blumenau e } \\
\text { região. }\end{array}$ & 182 & 1,00 & 5,00 & 3,88 & 0,96 \\
\hline $\begin{array}{l}\text { As pesquisas científicas do meu curso, como TCCs e } \\
\text { projetos de iniciação científica, valorizam uma } \\
\text { abordagem regional. }\end{array}$ & 182 & 2,00 & 5,00 & 4,07 & 0,80 \\
\hline $\begin{array}{l}\text { Algumas atividades desenvolvidas em sala de aula } \\
\text { também têm o propósito de integrar os alunos do curso } \\
\text { com o cenário local. }\end{array}$ & 182 & 1,00 & 5,00 & 4,23 & 0,81 \\
\hline Papel Pessoal na comunidade & 182 & 2,25 & 5,00 & 4,37 & 0,57 \\
\hline $\begin{array}{l}\text { Trabalhar em prol da minha comunidade me permite } \\
\text { ganhar uma nova perspectiva sobre as coisas. }\end{array}$ & 182 & 1,00 & 5,00 & 4,49 & 0,75 \\
\hline $\begin{array}{l}\text { Sinto-me importante quando realizo atividades que } \\
\text { ajudam os outros. }\end{array}$ & 182 & 2,00 & 5,00 & 4,70 & 0,61 \\
\hline $\begin{array}{l}\text { Na maioria das vezes, preocupo-me verdadeiramente } \\
\text { com as pessoas ou com as causas às quais me dedico. }\end{array}$ & 182 & 2,00 & 5,00 & 4,52 & 0,66 \\
\hline $\begin{array}{l}\text { Recebo incentivo das pessoas próximas a mim para } \\
\text { realizar atividades voluntárias, ajudando pessoas e a } \\
\text { minha comunidade. }\end{array}$ & 182 & 1,00 & 5,00 & 3,79 & 1,14 \\
\hline Papel da Comunidade na formação pessoal & 182 & 2,00 & 5,00 & 4,49 & 0,62 \\
\hline $\begin{array}{l}\text { Realizar atividades voluntárias também me ajudará a ter } \\
\text { sucesso na profissão. }\end{array}$ & 182 & 1,00 & 5,00 & 4,35 & 0,87 \\
\hline $\begin{array}{l}\text { Ter um envolvimento com a comunidade contribui para } \\
\text { a minha formação profissional, ampliando meus } \\
\text { conhecimentos e experiências. }\end{array}$ & 182 & 2,00 & 5,00 & 4,55 & 0,69 \\
\hline $\begin{array}{l}\text { Ter proximidade com o cenário local, conhecendo } \\
\text { diferentes aspectos econômicos, políticos e sociais da } \\
\text { comunidade, é um diferencial competitivo para o } \\
\text { profissional de Publicidade e Propaganda. }\end{array}$ & 182 & 2,00 & 5,00 & 4,57 & 0,64 \\
\hline Valorização da Extensão & 182 & 2,00 & 5,00 & 4,39 & 0,67 \\
\hline $\begin{array}{l}\text { Os projetos de extensão de Publicidade e Propaganda são } \\
\text { motivo de orgulho para os estudantes do curso. }\end{array}$ & 182 & 1,00 & 5,00 & 4,44 & 0,79 \\
\hline $\begin{array}{l}\text { Esses projetos divulgam o curso de Publicidade e } \\
\text { Propaganda junto à comunidade regional. }\end{array}$ & 182 & 1,00 & 5,00 & 4,45 & 0,79 \\
\hline $\begin{array}{l}\text { Esses projetos são considerados pelos alunos de } \\
\text { Publicidade e Propaganda um dos grandes diferenciais do } \\
\text { curso. }\end{array}$ & 182 & 1,00 & 5,00 & 4,28 & 0,87 \\
\hline $\begin{array}{l}\text { Valorização do Projeto Comunicação para o } \\
\text { Desenvolvimento Social }\end{array}$ & 182 & 2,67 & 5,00 & 4,67 & 0,49 \\
\hline Contribui para o desenvolvimento da cidade. & 182 & 2,00 & 5,00 & 4,78 & 0,50 \\
\hline $\begin{array}{l}\text { Aproxima e promove contatos entre estudantes e o } \\
\text { mercado profissional. }\end{array}$ & 182 & 2,00 & 5,00 & 4,62 & 0,61 \\
\hline Coloca em prática as teorias estudadas em sala de aula. & 182 & 1,00 & 5,00 & 4,62 & 0,69 \\
\hline
\end{tabular}

Tabela 2 Estatística descritiva

Fonte: dados da pesquisa 
Extensão universitária no curso de Publicidade e Propaganda: perspectivas acadêmicas e comunitárias do projeto comunicação para o desenvolvimento social

Como forma de analisar as inter-relações entre as variáveis, foi utilizada uma análise de correlações usando o método de Spearmann. Os resultados desta análise estão presentes na tabela 3, a seguir.

\begin{tabular}{lccccc}
\hline & $\begin{array}{c}\text { Papel da } \\
\text { Universidade }\end{array}$ & $\begin{array}{c}\text { Papel } \\
\text { do } \\
\text { Curso }\end{array}$ & $\begin{array}{c}\text { Papel } \\
\text { Pessoal }\end{array}$ & $\begin{array}{c}\text { Comunidade } \\
\text { na formação }\end{array}$ & $\begin{array}{c}\text { Valorização } \\
\text { da Extensão }\end{array}$ \\
\hline $\begin{array}{l}\text { Papel da } \\
\text { Universidade } \\
\text { Papel do }\end{array}$ & 1,000 & & & & \\
$\begin{array}{l}\text { Curso } \\
\text { Papel Pessoal }\end{array}$ &, $503^{* *}$ & 1,000 & & & \\
$\begin{array}{l}\text { Comunidade } \\
\text { na formação }\end{array}$ &, $433^{* *}$ &, $495^{* *}$ & 1,000 & & \\
$\begin{array}{l}\text { Valorização } \\
\text { da Extensão }\end{array}$ &, $342^{* *}$ &, $367^{* *}$ &, $462^{* *}$ & 1,000 & \\
$\begin{array}{l}\text { Valorização } \\
\text { do projeto }\end{array}$ &, $432^{* *}$ &, $336^{* *}$ &, $331^{* *}$ &, $258^{* *}$ \\
\hline $\begin{array}{l}\text { Tabela 3 - Correlações } \\
\text { Fonte: dados da pesquisa. }\end{array}$ &, $227^{* *}$ &, $319^{* *}$ &, $368^{* *}$ & \\
\hline
\end{tabular}

Conforme a tabela 3 indica, há algumas correlações entre as variáveis que importa apontar. Primeiro, há uma correlação forte entre o "Papel da Universidade" e o "Papel do Curso de Publicidade e Propaganda", que indica que a visão do estudante sobre a relação da comunidade com a universidade é muito próxima da sua visão da relação da comunidade com o curso. Também há uma relação forte entre o papel do curso e o papel pessoal para com a comunidade. Dessa forma, é possível inferir que os estudantes que percebem maior importância da sua função com a sociedade também tendem a notar maior relação entre a comunidade e o curso.

Destaca-se também a relação entre a valorização da extensão e a relação da comunidade com o curso. Essa relação é interessante pois mostra que os estudantes que dão maior valor para a extensão também tendem a reconhecer a importância da relação da comunidade com o curso, o que corrobora de forma geral a filosofia da extensão.

A seguir, realizou-se uma análise de mínimos quadrados parciais (PLS) com o objetivo de testar as hipóteses postuladas. Posteriormente, foi realizado um teste de bootstrap com os mínimos quadrados parciais com o objetivo de identificar quais relações seriam estatisticamente significantes. 
Extensão universitária no curso de Publicidade e Propaganda: perspectivas acadêmicas e comunitárias do projeto comunicação para o desenvolvimento social

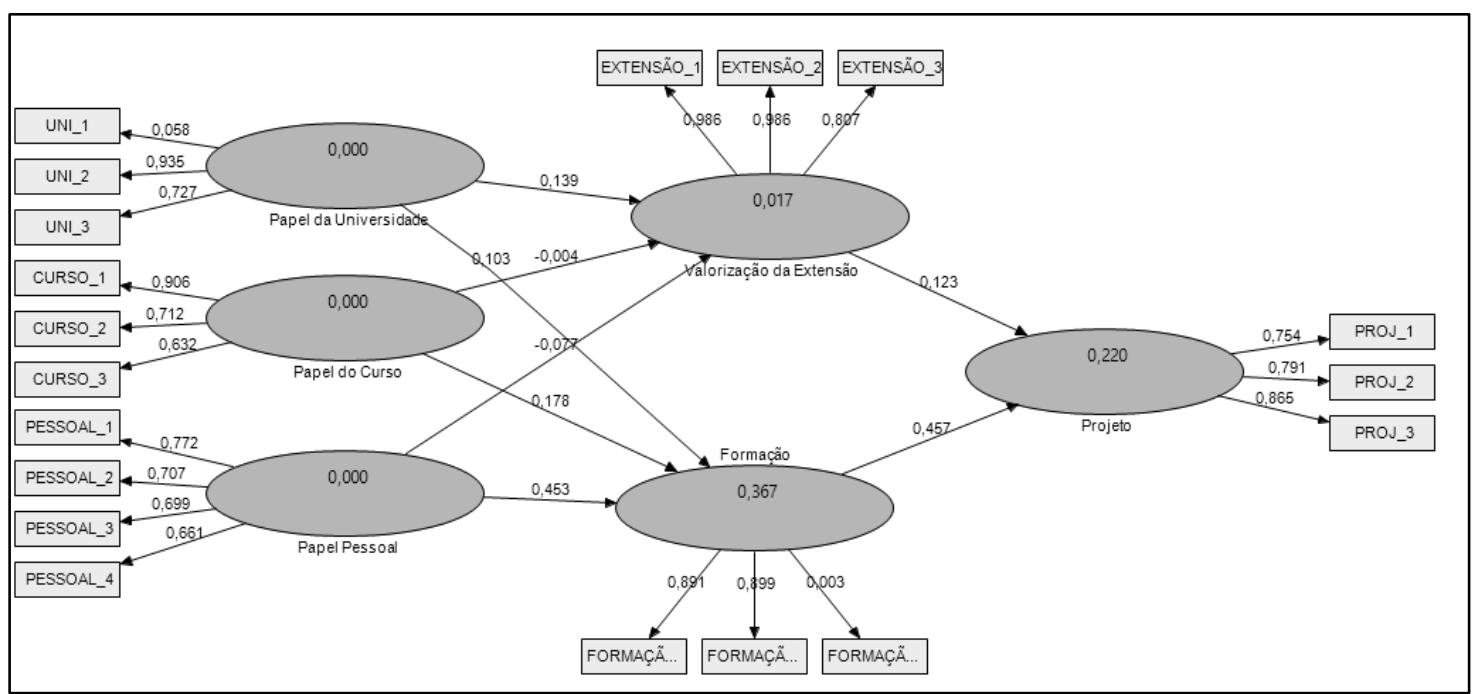

Figura 1: Teste de mínimos quadrados parciais (Partial Least Squares)

Fonte: dados da pesquisa.

Conforme é possível ver na figura 1 , dois dos construtos foram formados com um poder explicativo bastante alto, o da Comunidade na Formação $(r=0,367)$ e o da Valorização do Projeto $(r=0,220)$. Em contrapartida, o constructo da valorização da extensão não obteve qualidade explicativa muito alta, restringindo-se a apenas 1,7\% do fenômeno sendo explicado pelas relações traçadas. Para confirmar as hipóteses, foi utilizado o teste de bootstrap:

\begin{tabular}{|c|c|c|c|c|c|c|}
\hline Hipótese & Caminho & $\begin{array}{c}\text { Estatística } \\
\text { do teste } t\end{array}$ & Significante & $\begin{array}{l}\text { Sinal do efeito } \\
\text { previsto }\end{array}$ & $\begin{array}{c}\text { Efeito } \\
\text { observado }\end{array}$ & $\begin{array}{l}\text { Resultado da } \\
\text { Hipótese }\end{array}$ \\
\hline H1 & $\begin{array}{l}\text { Papel da Universidade -> } \\
\text { Valorização da Extensão }\end{array}$ & 3,959826 & $\operatorname{Sim}$ & + & + & Confirmado \\
\hline $\mathrm{H} 2$ & $\begin{array}{l}\text { Papel da Universidade -> } \\
\text { Formação }\end{array}$ & 2,120767 & $\operatorname{Sim}$ & + & + & Confirmado \\
\hline $\mathrm{H} 3$ & $\begin{array}{l}\text { Papel do Curso -> } \\
\text { Valorização da Extensão }\end{array}$ & 0,064536 & Não & + & $\begin{array}{c}\text { Não } \\
\text { significante }\end{array}$ & $\begin{array}{c}\text { Não } \\
\text { Confirmado }\end{array}$ \\
\hline $\mathrm{H} 4$ & $\begin{array}{l}\text { Papel do Curso -> } \\
\text { Formação }\end{array}$ & 4,387148 & Sim & + & + & Confirmado \\
\hline $\mathrm{H} 5$ & $\begin{array}{l}\text { Papel Pessoal -> Valorização } \\
\text { da Extensão }\end{array}$ & 1,569491 & Não & + & $\begin{array}{c}\text { Não } \\
\text { significante }\end{array}$ & $\begin{array}{c}\text { Não } \\
\text { Confirmado }\end{array}$ \\
\hline H6 & Papel Pessoal -> Formação & 10,70004 & $\operatorname{Sim}$ & + & + & Confirmado \\
\hline $\mathrm{H} 7$ & $\begin{array}{l}\text { Valorização da Extensão -> } \\
\text { Projeto }\end{array}$ & 3,849391 & Sim & + & + & Confirmado \\
\hline $\mathrm{H} 8$ & Formação -> Projeto & 10,03402 & Sim & + & + & Confirmado \\
\hline
\end{tabular}

À medida em que as relações propostas nas hipóteses foram testadas, constata-se que as hipóteses H1, H2, H4, H6, H7 e H8 foram confirmadas. Por outro lado, as hipóteses H3 e H5 não puderam ser confirmadas. Desta forma, é possível observar que duas relações propostas entre a visão do estudante sobre o curso e a visão sobre seu papel pessoal quanto à comunidade não têm efeitos significantes para a valorização da extensão como um todo. 
Extensão universitária no curso de Publicidade e Propaganda: perspectivas acadêmicas e comunitárias do projeto comunicação para o desenvolvimento social

Por outro lado, foram confirmadas as relações entre os papéis da universidade, do curso e do indivíduo para com a comunidade e a percepção da importância dessa relação com a sociedade na formação pessoal. Pode-se concluir que os estudantes que enxergam uma relação maior destes fatores com a comunidade também a veem como uma fonte que melhora sua própria formação.

Foram igualmente confirmadas as hipóteses que ligavam a valorização da extensão e a percepção da comunidade na formação com a valorização do projeto "Comunicação para o Desenvolvimento Social". Assim, é possível indicar que quanto mais o estudante vê a relação com a comunidade como algo benéfico para sua formação e quanto mais valoriza a extensão, maior será a valorização do projeto em si.

\section{CONSIDERAÇÕES FINAIS}

O presente artigo teve o objetivo de analisar a percepção do estudante de Publicidade e Propaganda da FURB em relação às diferentes dimensões da extensão universitária e especificamente ao projeto "Comunicação para o desenvolvimento social". A execução de práticas extensionistas no processo de ensino e aprendizagem na universidade contribui para melhorias na comunidade na qual ela se insere e, ao mesmo tempo, faz com que os acadêmicos possam refletir sobre o cenário local.

A partir dos resultados é possível indicar que a valorização da extensão é algo muito mais ligado com o papel da universidade do que com o curso especificamente ou do estudante em particular. Também é possível inferir, pelo fato de $\mathrm{o}^{2}$ da valorização da extensão ter sido baixo, que a valorização da extensão se dá independentemente dos outros fatores observados.

É importante insistir na afirmação de que a universidade não pode funcionar descolada do cenário social e alienada das grandes questões da atualidade. O papel institucional da universidade deve ir além da produção do conhecimento em sala de aula e a valorização da extensão faz parte de uma nova política institucional, que tem provocado grandes mudanças no ambiente organizacional educativo.

Sugere-se para futuros estudos a avaliação qualitativa das diferentes dimensões aqui apresentadas, assim como o diagnóstico a partir da comunidade atendida. 
Extensão universitária no curso de Publicidade e Propaganda: perspectivas acadêmicas e comunitárias do projeto comunicação para o desenvolvimento social

\section{REFERÊNCIAS}

BORDENAVE, Juan Diaz. A formação universitária exige integração e equilíbrio nos componentes do triângulo educativo. In: ROLLEMBERG, Marcelo. Universidade: formação e transformação. São Paulo: Edusp, 2005. p. 49-54.

BRASIL. Lei no 13.005, de 25 de junho de 2014. Aprova o Plano Nacional de Educação PNE. Brasília, DF, 2014.

CALDERÓN, Adolfo Ignacio. Extensão universitária: revisitando conceitos e práticas institucionais. In: CALDERÓN, Adolfo Ignacio; SANTOS, Sônia Regina Mendes dos; SARMENTO, Dirléia Fanfa (org.). Extensão universitária: uma questão em aberto. São Paulo: Xamã, 2011. p. 23-38.

CASTANHO, Sérgio Eduardo Montes. A universidade entre o sim, o não e o talvez. In: VEIGA, Ilma Passos Alencastro, CASTANHO, Maria Eugênia (org.). Pedagogia universitária: a aula em foco. Campinas, SP: Papirus, 2000, p. 13-48.

CHAGAS, Helena. Pela universidade pública, gratuita e de qualidade. O Globo, 25 jan. 2004, p. 3.

DEMO, Pedro. Professor/conhecimento. UNB, 2001. Disponível em: http://antigo.enap.gov.br/downloads/ec43ea4fProfessor Conhecimento.pdf. Acesso em: 12 mar. 2018.

FÓRUM DE PRÓ-REITORES DE EXTENSÃO DAS UNIVERSIDADES PÚBLICAS BRASILEIRAS (FORPROEX). Política Nacional de Extensão Universitária. Manaus: Forproex, 2012.

FRANTZ, Walter. Um olhar interpretativo sobre a extensão em universidades comunitárias. In: CALDERÓN, Adolfo Ignacio; SANTOS, Sônia Regina Mendes dos; SARMENTO, Dirléia Fanfa (org.). Extensão universitária: uma questão em aberto. São Paulo: Xamã, 2011. p. 125-138.

FREIRE, Paulo; SHOR, Ira. Medo e ousadia: o cotidiano do professor. 10. ed. Rio de Janeiro: Paz e Terra, 2003.

GHEDIN, Evandro. Professor reflexivo: da alienação técnica à autonomia crítica. In: PIMENTA, Selma; GHEDIN, Evandro (org.). Professor reflexivo no Brasil: gênese e crítica de um conceito. 3. ed. São Paulo: Cortez, 2005. p. 129-150.

GÖRANSSON, Bo; MAHARAJH, Rasigan; SCHMOCH, Ulrich. Introduction: new challenges for universities beyond education and research. Science and Public Policy, v. 36, n. 2, p. 83-84, 2009.

JANNE, Henri. A universidade e as necessidades da sociedade contemporânea. Fortaleza: UFC, 1981.

MENESES, Paulo. Universidade e diversidade. Recife: Unicap, 2001. 
Extensão universitária no curso de Publicidade e Propaganda: perspectivas acadêmicas e comunitárias do projeto comunicação para o desenvolvimento social

MINAYO, Maria Cecília de Souza. Mudança: conceito-chave para intervenções sociais e para avaliação de programas. In: MINAYO, Maria Cecília de Souza; ASSIS, Simone Gonçalves de; SOUZA, Edinilsa Ramos de. Avaliação por triangulação de métodos: abordagem de programas sociais. Rio de Janeiro: Fiocruz, 2005. p. 53-70.

PEREIRA, Luisa. Ensino superior no mundo contemporâneo: desafios e perspectivas. Refeol, v. 1, n. 1, 2011, p. 1-21. Disponível em http://www.feol.com.br/sites/Revista\%20eletronica. Acesso em: 13 mar. 2018.

ZUCCO, Fabricia D.; QUADROS, Cynthia M. B.; BONA, Rafael J. A extensão na graduação em Publicidade e Propaganda: imagem institucional, envolvimento comunitário e práticas de ensino. In: VIII PROPESQ PP - ENCONTRO NACIONAL DE PESQUISADORES EM PUBLICIDADE E PROPAGANDA, 2017, Recife/PE. Ebook do VIII PROPESQ-PP [recurso eletrônico] / Rogério Covaleski (Org.). Recife/PE: Ed. UFPE, 2017. p. 1106-1121.

ZUCCO, Fabricia D.; QUADROS, Cynthia M. B.; REIS, Clóvis; BONA, Rafael J.. Extensão Universitária: experiências do projeto Focus do curso de Publicidade e Propaganda da FURB. In: VII PRÓ-PESQ PP - ENCONTRO NACIONAL DE PESQUISADORES EM PUBLICIDADE E PROPAGANDA, 2016, Rio de Janeiro/RJ. Anais, 2016. p. 1205-1215.

Recebido em: 11/02/2019

Aceito em: 05/11/2019 